\title{
PLANT PHENOLICS INTO PHYTOCHEMISTRY
}

\author{
By DR. E. C. BATE-SMITH, C.B.E. \\ Low Temperature Research Station, Cambridge
}

\section{Origin and History of the Plant Phenolics Group}

$\mathrm{T}$ WELVE years ago a meeting was held at Long Ashton Research Station, near Bristol, which proved to be the starting point of a highly rewarding adventure. This meeting on plant tannins was organized jointly by Long Ashton and the Low Temperature Research Station at Cambridge, and the invited guests were from other food research laboratories, from leather and forest product research laboratories, and from university departments of botany and chemistry, including those of the University of Bristol. It was here that 'phenolics' were christened and the foundation laid, although unwittingly, for the formation, five years later, of the Plant Phenolies Group.

It is interesting to recall why the Group met such an immediate and enthusiastic response. So far as plant physiology was concerned, the function of the phenolic constituents was unidentified and apparently unimportant. Lignification was an event taken more or less for granted, of concern only to the plant anatomist and the paper industry, tannins had no evident function and, together with many of the simple phenolic constituents, could most conveniently be regarded as waste products of organisms unprovided with excretory apparatus. The phenolases might perhaps be concerned with respiration, but could not be shown to play any such part in normal physiological processes. Only the anthocyanins of flowers and fruits could be allocated a role in fertilization and seed dispersal. Since there was no one in the world of botany to take an interest in the phenolic constituents of plants, the chemists set out to look after the field themselves.

A start had been made in 1947 in the application of paper chromatography to the anthocyanins and flavones of flower petals; but it was Dr. A. E. Bradfield, working for the Indian Tea Association in the laboratories of J. Lyons and Co., Ltd., and later at East Malling Research Station, who really set the wheels in motion. Making skilful use of partition chromatography, he separated a number of fractions from the tea tannins and showed them to be the 3-galloyl esters of catechin and gallocatechin, then, using paper chromatography for the first time as an analytical tool in phenolic chemistry, he and I established the configuration of the diastereoisomers of the gallocatechins and their galloyl esters. Although, unfortunately, he died before it came into being, it was his authority as a chemist which underpinned the phenolics group in its formative period. His work for the Indian Tea Association and his support of the Group were vigorously carried on by his successor, Dr. E. A. H. Roberts, who later became the second chairman of the Group.

The Plant Phenolics Group was broadly based to cater for the botanist and the chemist, for the university scientist and for the technologist in industry. The subject for discussion at the inaugural meeting at Cambridge, in June 1957, "The Oxidation of Plant Phenolics", was chosen to attract as numerous and representative an attendance as possible. The same objective governed the selection of subjects for discussion at subsequent annual general meetings, the Proceedings of which have nearly all been published.

In addition to these annual general meetings, two meetings a year were held on more narrowly based topics. The last of these, foreshadowing the widening of the field which had already been decided on, was a symposium on "The Comparative Biochemistry of the Leguminosae", a subject still largely phenolic in its content, but including also alkaloids, unusual amino-acids, seed proteins and carbohydrates.

\section{Evolution of a Phytochemical Group}

The Plant Phenolics Group had no difficulty in finding attractive subject-matter for three meetings a year, even though the field is a restricted one. The question of an extension of the Group's activities had, however, always been in the minds of successive committees. It had been hoped that other limited subject-areas of phytochemistry might be similarly developed, so that in due course a 'super-group' might be formed co-ordinating the separate activities of a number of such associations. However, many members of the Group were interested in other kinds of plant constituents such as terpenes, alkaloids, carotenoids and amino-acids, and since there was no indication that the group would be trespassing on other people's ground if these were absorbed into its activities, a move was made two years ago to test the feelings of the members about expanding the Group to include the whole range of secondary plant constituents. Finally, at the annual general meeting in April, 1964, the Plant Phenolics Group voted itself into a new phase of existence as the Phytochemical Group.

There are many consequences of this expansion of activity. First, of course, the membership can be expected to increase and, secondly, the programme will inevitably become to some extent sectionalized. But one thing above all else the present Committee wishes to preserve is the comfortable informality of the Group's proceedings. This desire for informality is behind the choice of title; a group can be as formal or informal as it pleases.

There is also a deliberate intention in the choice of 'Phytochemical' as the descriptive element in the title, both a broader and a narrower intention than would be implied, for example, by 'Plant Chemical' or 'Plant Biochemical'. Perhaps the nearest one can get to a definition is that there is at all times an effort to understand the significance of the chemical constituents, especially the secondary constituents, in the life of the plant, and the effect they may have on the lives of man and animals. These objectives give point to the work of the chemist in isolating and characterizing new natural products, and fortify the plant physiologist with knowledge of the identity and possible function of these plant constituents.

There is one reason why the formation of a Phytochemical Group is especially timely, and that is the rapid growth of chemical taxonomy, or biochemical systematics. While much of the initiative for this outburst of activity has come from the chemical side botanists are equally prominent. One international conference has already been held, and its Proceedings have been published. ${ }^{1}$. An outcome of this conference has been the proposed formation of a Chemical Taxonomy Commission of the Organic Chemistry Section of International Union of Pure and Applied Chemistry, and the creation of a formal link between this and a recently formed committee of the International Association of Plant Taxonomists.

This comes at a time when there is much searching-and some burning - of heart among plant taxonomists themselves, and indeed among classifiers and systematizers of knowledge generally. It can be foreseen that chemical characters will be needed, although reluctantly admitted, along with anatomical, cytological and palynological characters, as adjuncts to the characters of classical taxonomy, which seem to be reaching the limits of their unaided application to problems of classification. All this interest will promote activity among the members of the Phytochemical Group and will be strongly reflected in its programme. Indeed, the subject of the first annual general meeting of the new Group, which was held in 
Cambridge in April, 1965, was a three-day symposium on "Comparative Phytochemistry", a roport of which is given in the following article.

Much of the knowledge of the chemistry of plants has been gained by the search for pharmacologically active substances, so that the applications of phytochemistry in the pharmaceutical field can also be expected to be prominently featured in the Group's programme. But there is a field of at least equal interest and importance in the occurronce of physiologically active compounds in actual or potential foods and feeding-stuffs. Outstanding examples of those are the oestrogens in leguminous crop plants and the recent discovery of aflatoxin in spoiled groundnuts. Besides these harmful constituents there is $a_{0}$ growing neod for chemical knowledge-and, in gas chromatography, the means of obtaining it-of the nature of aroma substances in foods. It is to these constituents that so much of the attractiveness, or unattractiveness, of food is due. Both in the breeding and growing of the fresh foods, and in the preservation and enhancement of fresh quality the demand is for an understanding of the nature of the aroma substances. Just as our knowledgo of the pigments has advanced during tho past fow years so our knowledge of the 'aromatics' can be expected to grow during the coming years, and these aroma substances cover a far wider range than the comparativoly fow kinds of substances to which the plant pigments are confined. The usefulness of this knowledge can be expected to extend, and is, indeed, already extending, to tho palatability of animal feeding-stuffs, now that intensive feeding mothods are beginning to assume so much importance in stock raising and dairy farming.

While some regard must be given to sectional interests in the activities of the Group, its objectives will be much better promoted by emphasizing the more general aspects of phytochemistry. With the increasing complexity and specialization both of academic chemistry and the various branches of industry thore is a tendency for departmentation and segregation to increase. It will be one of the great advantages of meetings of the Group that departmental barriers can be broken down in the discussion of such topics as biosynthesis and chemical taxonomy, subjects which not only embrace the whole range of natural products, but which also possess an exciting and rewarding intellectual content. These are satisfying activities for the increasing number of those for whom chemistry for chemistry's sake and botany for botany's sake are not enough.

${ }^{1}$ Chemical Taxonomy, edit. by Swain, T. (Academic Press, 1964).

\title{
COMPARATIVE PHYTOCHEMISTRY
}

\author{
By DR. J. B. HARBORNE \\ John Innes Institute, Bayfordbury, Hertford
}

$\mathrm{A}^{\mathrm{N}}$

$\mathrm{N}$ international symposium on comparative aspects of plant chemistry, organized by the Phytochemical Group with the financial assistance of the Scientific Affairs Division of NATO, was held in Cambridge during March 30-April 1. The main theme of the meeting was the taxonomic implication of the natural distribution of the various groups of plant constituents, but their biogenesis, evolution and general biochemistry were also discussed. The taxonomist's view of phytochemistry was given by Prof. V. H. Heywood (Liverpool) in the introductory lecture. He dealt with the problems of incorporating chemical data into classification and showed why it was impossible to recommend the phytochemist to uso one rather than another of the various plant elassifications that are available. He pointed out that a number of systems will always be needod to fulfil different objectives.

In a second introductory lecture, Prof. C. R. Mentzer (Paris) oxpounded his well-known biogenetic classification of plant constituents, in which substances are placed together according to their biogenetic origin rather than on the basis of chemical complexity as in Beilstein.

The first main session, under the chairmanship of Prof. L. Fowdon, was dovoted to the distribution of nitrogenous compounds. Dr. E. A. Bell (London) described the distribution patterns of non-protein amino-acids ho had obtained using paper eloctrophoresis of legume seod extracts. These patterns, he said, could be used to divide each of the genera Lathyrus and Vicia into several distinctive biochermical groups. Ho pointod out that comparisons of biosynthetic pathways were probably more valuable with unusual amino-acids than considerations of the distribution of single compounds. Prof. R. Hegnauer (Leiden), in considering the taxonomic significance of the comparative chemistry of the alkaloids, found many examples of parallelism and diversification. One of the conspicuous successes of chemical taxonomy has been the discovory that betacyanins and betaxanthins are restricted to one order of plants, the Centrospermae, and the final paper in this session, given by Dr. T. J. Mabry (Texas), dealt with these purple and yellow alkaloidal pigments.
After describing the chemistry of these substances, Dr. Mabry considered the various arrangements that have been proposed for the betacyanin-containing families and showed that his results definitely discounted the Hutchinson system in this context.

The second session was devotod to phenolic constituents and included a consideration of hydroxyquinones (Dr. C. Mathis, Strasbourg), dihydrochalcones (A. H. Williams, Bristol), glycoflavones (Prof. H. Wagner, Munich) and flavonoid pigments (Dr. J. B. Harborne, John Innes Institute). It was clear from these papers that although phenolics are among the most promising of taxonomic markers, they have not as yet made much contribution to plant systematics. For example, the dianthrone hypericin, as Dr. Mathis found, is characteristic of the genus Hypericum, but it only occurs in about half of the 300 species examined. One difficulty in evaluating the results of surveys is the occurrence of 'chemical races' within a single species. A dramatic example of this phenomenon was uncovered by A. H. Williams, who found that some samples of the dihydrochalcone-containing Smilax glycyphylla either lacked phenols altogether or contained the xanthone, mangiferin, instead. Glycoflavones aro more widely occurring than dihydrochalcones but little is known of their detailed distribution at the generic level. Ono of the main difficulties with glycoflavones is distinguishing them from the more common flavone $O$-glycosides, and Prof. Wagner dealt mainly with this aspect of their phytochemistry in his lecture. Because of thoir importance as petal pigments, the flavonoids are very interesting from an evolutionary point of view, and Dr. Harborne, therefore, sought correlations between flavonoid structures and evolutionary advancement. $\mathrm{He}$ also described some rocent surveys in the Gesneriacea $\theta$ and Plumbaginacea $\theta$, in which novel correlations have been found between anthocyanin distribution and pollen or leaf morphology.

The third session, under the chairmanship of Prof. $H$. Erdtman (Stockholm), dealt with hydrocarbons and thoir derivations. Dr. G. Eglinton (Glasgow) said that the alkane distributions so far studied indicated a reasonable 